\title{
High Temperature Baking Test System Design and Implementation
}

\author{
Lu Liang $^{\mathrm{a}}$, Ma Hong ${ }^{\mathrm{b}}$, Hu Yupeng ${ }^{\mathrm{c}}$
}

Institute of Systems Engineering,China Academy of Engineering Physics 621900,Mianyang,China

aemail:dl-lu@163.com, bemail:dsymay@163.com, ${ }^{\mathrm{c}}$ email:yupengbao@163.com

Keywords: Bonfire Environment; Baking Test; Auto-tuning PID Regulator

\begin{abstract}
To simulate the unexpected bonfire environment during weapon's life time, a high temperature baking test system is established. It chooses the high-temperature furnaces as heating terminal, develops a heat control instrument and programs the computer monitoring software. Considering the problems of the high temperature control, such as time-variant parameters, nonlinear and large time delay, a auto-tuning PID regulator is established. The heat terminal,monitoring software and auto-tuning PID regulator constitute the baking test system which could simulate bonfire environment with the heating range up to $700^{\circ} \mathrm{C}$ and heating rate up to $200{ }^{\circ} \mathrm{C} / \mathrm{min}$. The experimental verification demonstrates that the results show the system meets the requirements of temperature control and could be used for the unexpected bonfire environment.
\end{abstract}

\section{Introduction}

During the use life, Weapon products may encounter accidents like electrical short or crashes, which is able to cause weapons on fire. Considering the unusual fire circumstances could pose weapons safety hazards, Designer should take some protections to solve the unusual fire circumstances problem during the design phase and carry out experiments to verify their validity[1-4]. Luo Qunsheng,Shi Guangmei investigated the methods of weapons' fire test home and abroad, made studied about the test techniques and set up a oil pool fire test system which could provide a bonfire environment[5]. But there are some inconveniences about oil pool fire test system. For example, conducting a fire test will cost manpower and resources, the burning oil pool has a certain security risks, test is vulnerable to weather and weapons have complex composition, it is impossible to carry out each ministry component to the fire test assessment. For all the above reasons, in order to find out shortage and expose problems of a weapon's components in abnormal high temperature fire environment, the author made a selection of the heating terminal and designed a temperature controller and programmed the moniting software.

\section{Design of the Baking Test System}

According to GB11806-2004 "Safe Transport of Radioactive Material Regulations" [6]and to get a more accurate simulation about fire environment, baking test conditions are specified. The baking test system needs to achieve the ability to simulate temperature range of $700{ }^{\circ} \mathrm{C}$, the maximum heating rate should reach $10^{\circ} \mathrm{C} / \mathrm{min}$ and the temperature tolerances is $10^{\circ} \mathrm{C}$.

High pressure, explosive sections of test pieces have a certain risk under high temperature conditions, so the test system needs to have remote control capability and the test should be carried out at protective venues, so a safe test site was chosen. According to the test requirements, we designed a sample test ,purchased a furnace as a heating terminal which index as shown in Table 1.

The temperature control system is consisted of Monitor-Field level. Field level is composed by the field temperature controller and the heating terminal. This level accomplishes heating, temperature measuring and temperature control function. In the baking furnace, the heating temperature exceeds $700^{\circ} \mathrm{C}$, so K-type thermocouple temperature is used to collect temperature information. Field temperature controller obtains temperature signals from K-type thermocouple sensor, transmits them to the PC software by RS485, calculates the percentage of the heating output and controls the heating power of the baking furnace. 
Table 1 SG2-15-9 baking furnace technology parameters

\begin{tabular}{|l|l|}
\hline & Technical Specifications \\
\hline Rated Power & $15 \mathrm{~kW}$ \\
\hline Power supply & $380 \mathrm{~V} / 3 \mathrm{P} / 50 \mathrm{~Hz}$ \\
\hline Rated temperature & $1000^{\circ} \mathrm{C}$ \\
\hline Heating rate & $20^{\circ} \mathrm{C} / \mathrm{min}$ \\
\hline Dimensions & $920 \mathrm{~mm} \times 750 \mathrm{~mm} \times 1210 \mathrm{~mm}$ \\
\hline The heating element & U-type silicon carbide $\phi 16 \mathrm{~mm} \times 400 \mathrm{~mm}$ \\
\hline Work Size & $\phi 400 \mathrm{~mm} \times 700 \mathrm{~mm}$ \\
\hline
\end{tabular}

Monitoring program is designed to run on the PC side, it can get real-time temperature informations transferred from field temperature controller and records these informations to the local database for future reference. At the same time, monitoring program can achieve the functions to set test conditions parameters, display real-time temperature curve, historical data query, play and stop control the test equipment.

Field machine hardware schematics and monitoring software function as shown in Figure 1, Figure 2.

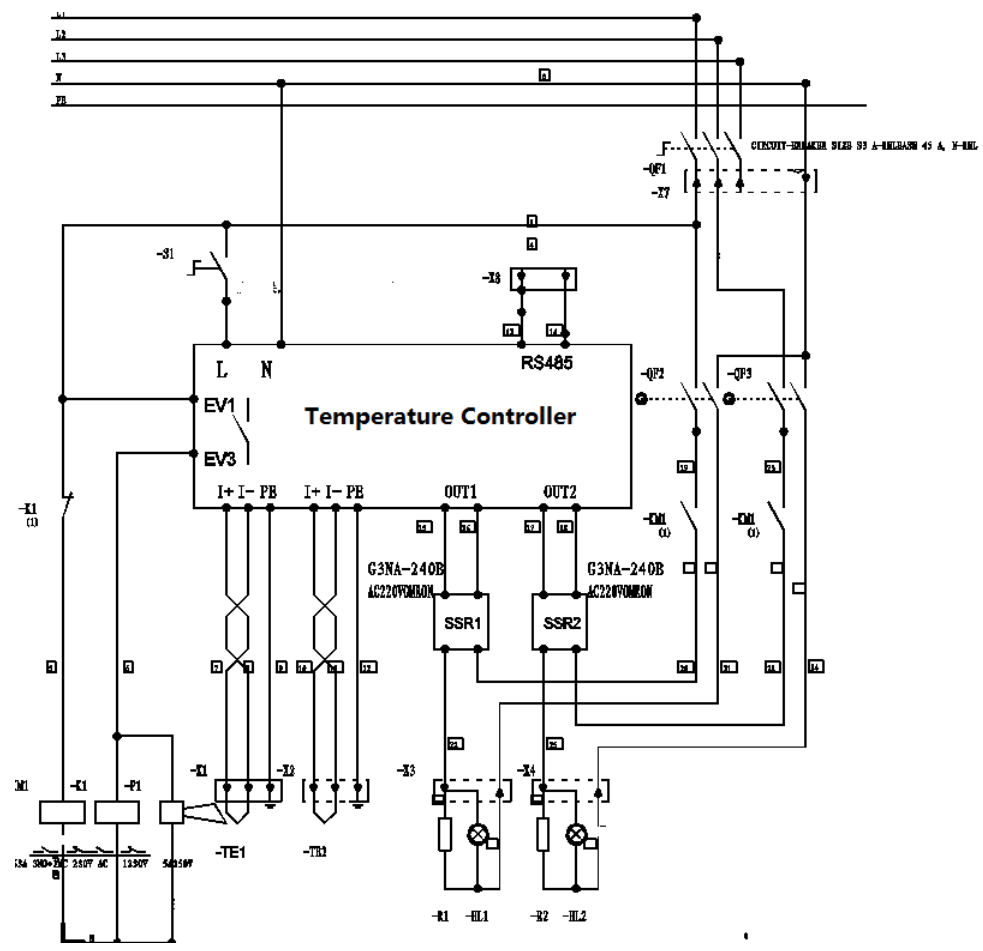

FIG.1. Field machine hardware schematics of the baking test system

\section{Temperature control algorithm}

The real-time temperature should have a good following performance to the set one, but as this test has a large temperature range, the temperature characteristics of fast heating rate, the thermostat model has changed, hysteresis, nonlinear features, so the traditional PID control method is difficult to meet the requirements of this experiment conditions[7-9].

Since the traditional PID control method is lack of adaptability to changable thermostat model, while adaptability of change of the fuzzy control is good, but it is unable to eliminate the steady-state error, so temperature control strategy was adjusted. The method of adjusting the thermostat parameters combines segmented control thoughts and ideas of fuzzy control[10]. First, the heating rise condition is divided to several temperature ranges, in each temperature range, some 
temperatures is selected to be the feature points of this range, based on which the temperature control parameters are able to calculated. By this method, the fuzzy control domain is converted to a specific value within a certain range. The uncertainties brought by the introduction of the domain thought reduce. Meanwhile, fuzzy control theory is referred when the temperature response model has changeable, nonlinear characteristic. The temperature deviation value and the rate of change are seen as input amount of the deviation, PID control parameters are adjusted by parameters adaptive control regulator designed which follows the principle of fuzzy control and traditional control are able to adjust parameters automatically and could improve temperature control parameters adaptiveable and anti-disturbance capacity. PID self-tuning controller structure is shown in Fig 3.

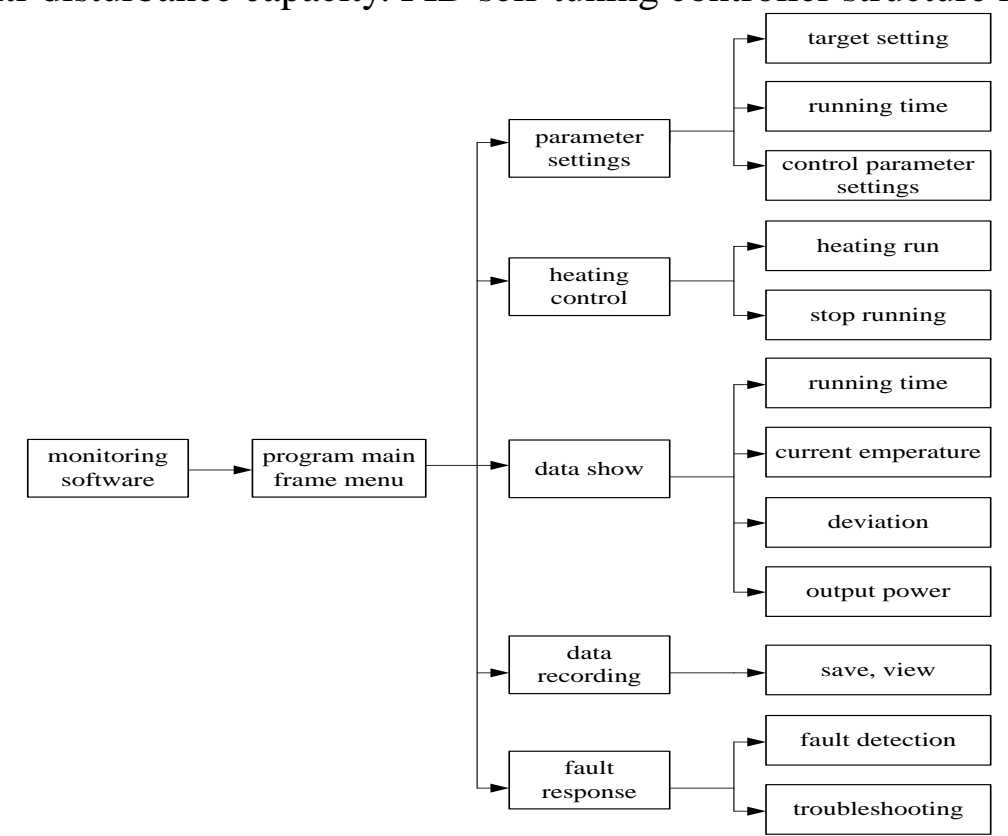

FIG.2. monitoring software functions of the baking test system

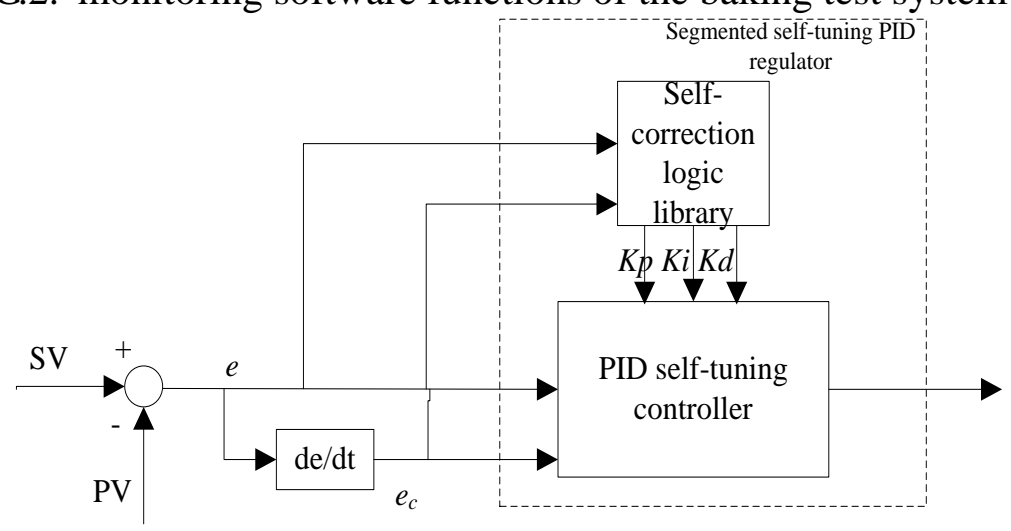

FIG.3. PID self-tuning controller structure

\section{Implement monitoring software functions}

According to the functional design requirements in Figure 2, the PC monitoring software that enables PC monitoring software features is programmed. The main interface of baking test system monitoring software is shown in Figure 4. Interface GUI design is the use configuration technology to achieve. Program software uses ForceControl 6.1 configuration software from three-dimensional control, Ltd. Beijing. The interface of the heating system is designed; real-time temperature information is wrote down into a local database; communication software between the temperature control device FP23 and PC is commissioned; also a script language is wrote, the features include: Call temperatures files, the preparation of the control algorithm, the self-tuning PID parameter control during the temperature rise in baking test.

Design and implementation of configuration technology-based software includes the following 
steps: Create the GUI, I /O device configuration, database configuration, animation connections [11], etc.

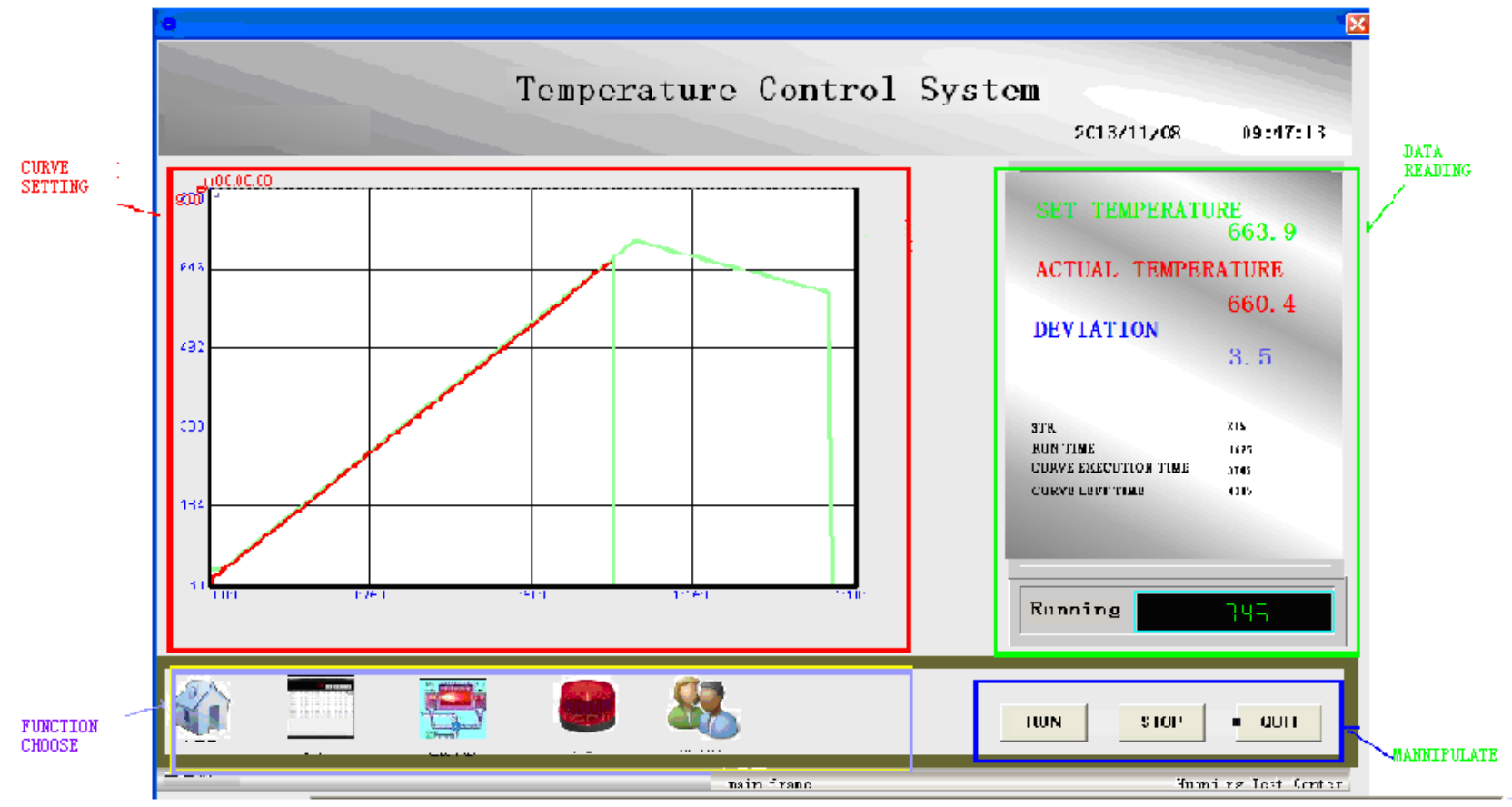

FIG.4. The main interface of baking test system monitoring software

\section{Test items and Instruments}

Test system consists of K-type thermocouple temperature gauge and MGC data acquisition components. Test systems and measuring point layout block diagram are shown in Figure 5. Due to the high temperature of this test which is higher than the traditional high-temperature plastic suitable operating range, it involves the development of high-temperature sensors, fixed and other technical during the test.For details, see literature [12].

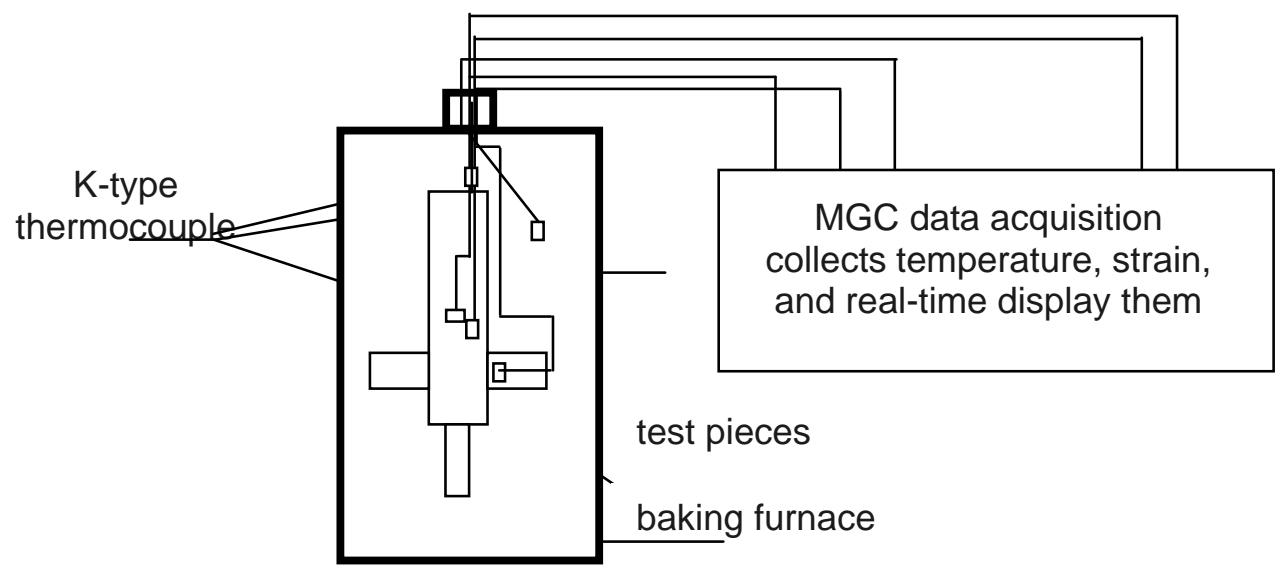

FIG.5. Test system diagram

\section{Experimental verification}

According to the experimental conditions, a fire resistance experiment is made. The temperature load resulting curve is shown at curve settings area in Figure 4, the green line is temperature set line and the red line is actual temperature curve, it can be seen in Figure 4 the deviation is less than $4{ }^{\circ} \mathrm{C}$ at $600^{\circ} \mathrm{C}$,the temperature rising rate is $10^{\circ} \mathrm{C} / \mathrm{min}$, meets the requirments about temperature.

System adaptive temperature parameters and the heating power output percentage are shown in 
Figure 6. Changes of the heating output and PID parameters were unilateral, smooth curves, within the characteristics of a corresponding change. This shows that the control algorithm is valid.The results meet the expecte. As the temperature rises, the heating power of the system rises, and the PID temperature control parameters ,I value is reducing while temperature is rising for example ,can be adjusted by self-tuning regulator.

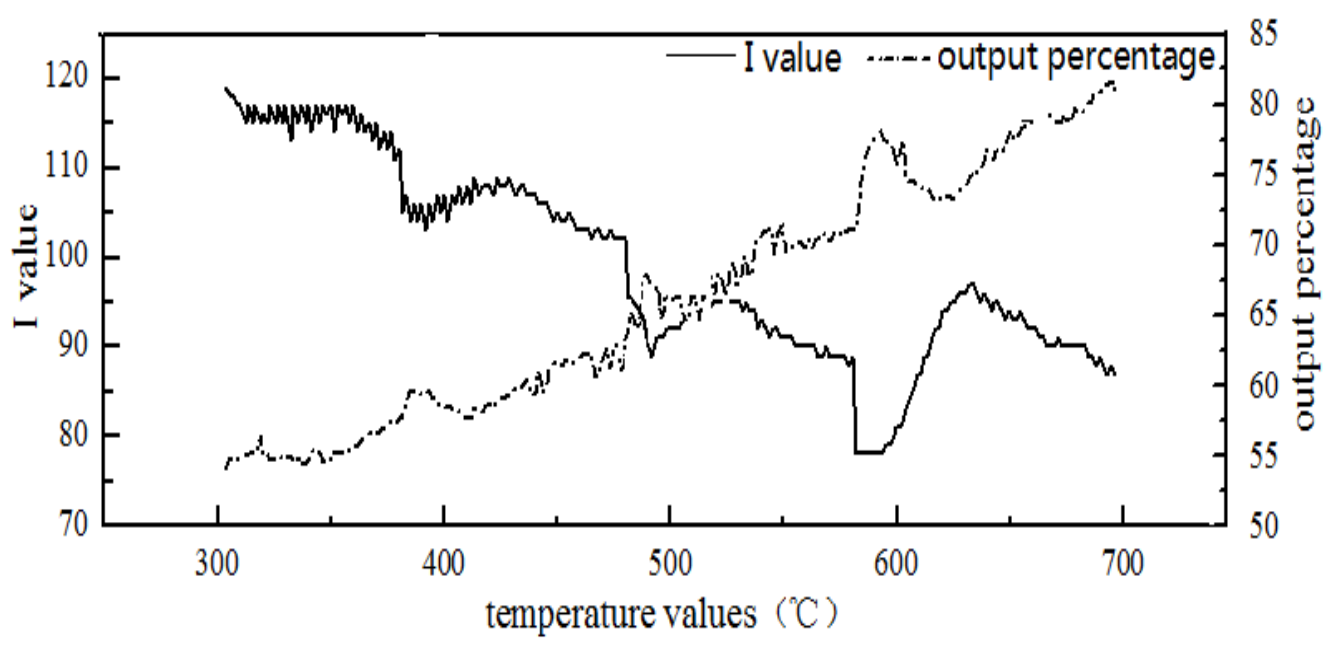

FIG.6. The heating output of Load test and auto-tuning temperature parameter curve

\section{Conclusion}

In order to simulate the weapons fire accident, a baking test system was established. The system uses furnace as heating terminal, establishes monitor-field level control structures, uses of configuration technology to complete the interface design. As the simulation model of the fire environment temperature changes, the lag nonlinear problems, piecewise fuzzy PID control regulator is introduced to meet the relevant provisions of the protocol and transport environmental standard. Through the designed experimental verification, this high temperature baking test system can be used to simulate the $700{ }^{\circ} \mathrm{C}$ heat, $10^{\circ} \mathrm{C} / \mathrm{min}$ temperature rising with the deviation less than $10^{\circ} \mathrm{C}$ of the aberrant fire environment, it can be used to undertake the baking test task and provide technical support for weapons protection design in aberrant fire environment.

\section{References}

[1] M.MUNOZ, J.ARNALDOS and J.CASAL, Analysis of the Geometric and Radioactive Characteristics of Hydrocarbon Pool Fire, Combustion and Flame [J], 2004 (139) 263-277.

[2] P.K.RAJ, LNG Fires: A Review of Experimental Results, Models and Hazard Prediction Challenges, Journal of Hazardous Materials[J], 2007 (140) 444-464.

[3] F.FERRERO, M. MUNOZ, Effects of Thin-layer Boil over on Flame Geometry and Dynamics in Large Hydrocarbon Pool Fires, Fuel Processing Technology[J], 2007 (88) 227-235.

[4] Guangmei Shi, Minghai Li , Shaoquan Hu, Effects of Cross Wind on kerosene Pool Fire Test, Equipment Environmental Engineering, [J], 2010 (7) 86-90.

[5] Guangmei Shi, Zhongli Zhang, Shaoquan Hu, Numerical Research on Flame Characteristic of a Three-meter Diameter Kerosene Fire, China Safety Science Journal[J], 2010 (9) 39-43.

[6] GB 11806-2004 Regulation for the safe transport of radioactive material. 
[7] Sajad Tabatabaee, Pegah Roosta, Mokhtar Sha Sadeghi: Fuzzy PID controller design for a heat exchanger system:The energy efficiency approach, International Conference on Computer Applications and Industrial Electronics[C] 2010.511-515.

[8] Caifu Liu , Lihua Liang and Juanjuan Gao, Fuzzy PID control of space manipulator for both ground alignment and space applications, International Journal of Automation and computing[J], 201411 (4) 353-360.

[9] Fenyi Guo, Huanqiang Zhang, The application of fuzzy PID control in coal mining area in automatic loading system, Computer measurement and control[J], 2013 (21) 1803-1806.

[10]K Ahn, D Truong , T Thanh, Online Self-tuning Fuzzy Proportional-integral-derivative Control for Hydraulic Load simulator, Proceedings of the Institution of Mechanical Engineers, Part I: Journal of Systems and Control Engineering[J],2008 222 (2) 81-95.

[11]Liang Lu, Application of Temperature Test system based on DDE. Modern Electronic Technique[J], 2014 (4) 90-92.

[12] Hong Ma, Fuel transport container heat resistance test. China space ten network professional information network [C] , Weihai 2014.143-146. 